\title{
UNA ENTREVISTA MÁS, UNA ENTREVISTA MENOS
}

POR

\author{
MIGUEL ÁNGEL CAMPODÓNICO \\ Montevideo
}

Uruguayo (según los tradicionalistas fundamentales debería decirse oriental), nació y vive en la ciudad de Montevideo (la única del país). En una República sin nombre (apenas se la conoce por la referencia a su ubicación geográfica), dio a conocer su primer libro tardíamente (para él). Alguna vez dijo que una de las pocas culpas de la que nunca se responsabilizó a la dictadura de los años 70'fue, precisamente, que él se decidiera a publicar en ese período. Pero la culpa existe y la historia no la absolverá. Publicó Blanco, inevitable rincón (1974), Donde llegue el Río Pardo (1980), Descubrimiento del cielo (1986), La piscina alfombrada (1988), Instrucciones para vivir (1989) y Hombre sin palabras (Edición francesa, bilingüe, 1991). Cuentos suyos aparecieron en varias antologías uruguayas y en revistas de Estados Unidos, Argentina, Suecia y Francia. Premiado varias veces, se pregunta diariamente (generalmente por las mañanas) cómo pudo obtener tanto escribiendo lo que escribe.

Se asegura que algo anda mal en la literatura de su país.

Al contrario. Esos son comentarios resentidos. Nosotros hemos llegado al punto ideal: tenemos más escritores que lectores. En realidad, la literatura en el Uruguay se parece a un ómnibus a las siete de la tarde: está "completa". Escritores hay que hasta deben hacerse lo que nosotros llamamos la "coladera" para no quedar a pie. Pocos países - ni siquiera del mundo desarrolladopueden jactarse de algo parecido.

Suena un poco exagerado.

Entiendo que a los extranjeros les parezca una exageración. Perole aseguro que no conozco nada más emocionante que las colas de escritores frente a las editoriales esperando que les permitan pagar las ediciones de sus libros.

Tantos escritores, entonces, habrán dado lugar a una fuerte corriente crítica, de análisis serio, riguroso, en profundidad.

Efectivamente. La crítica uruguaya es rigurosa, profunda y analíticamente periodística. Hay páginas de seminarios y diarios que gozan de más prestigio que otras, pero todas encontraron el mismo camino para que los opinadoresperiodistas expresen sus deseos sobre cómo les hubiera gustado a ellos que la obra reseñada hubiera sido escrita. Quienes intentan hacer crítica en medios 
distintos (libros, por ejemplo) quedan en minoría. De este modo se logra que todo el público tenga acceso a las páginas periodísticas y conozca los deseos de los opinadores. Como usted comprenderá, creemos haber llegado a la socialización de la crítica. Basta de libros elitistas que con el cuento de la teoría confunden a los lectores. Además -y esto hay que subrayarlo- nadie se lava las manos. Cada opinador se arriesga y emite calificaciones, aun las más severas. El amplio espectrova, por ejemplo, desde "Rodríguez puede y debe rendir más"o "Fernández se distrae y deberá copiar cincuenta veces el final del tercer capítulo”, hasta "Pérez deberá concurrir a la Redacción del seminario acompañado de sus padres".

¿Y cómo reaccionan los autores?

Los más impresionables se apresuran para esconder los diarios y los semanarios para evitar que sus padres los lean. Los atrevidos, en cambio, esos revoltosos que nadie aprueba, promueven paros de "máquinas de escribir caídas”.

¿Para qué escribe?

Me resulta difícil decir algo original. Ya lo repetí sesenta y dos veces. Escribo para molestar, para despertar, para desacomodar, para agobiar, para gritar, para acosar, para hostigar, para impacientar, para jeringar. (¿Le parece que tantos verbos de la primera conjugación en infinitivo caerán bien?)

La realidad de su país seguramente aparecerá en su obra.

Sí y no. En realidad trato de elevarme sobre ella, pero no estoy muy seguro de lograrlo. De cualquier modo, me causa gracia los comentarios de quienes sostienen que alguien como yo no puede ser uruguayo (oriental) porque no tomo mate, no juego al truco y me aburre el tango.

¿Se considera un europeizado?

Tenemos mala conciencia, nos da vergüenza sentirnos más cerca de un español o de un italiano que de un guatemalteco o de un boliviano. Ése es nuestro pecado: no somos europeos ni latinoamericanos. Ahora estamos más cerca de los países del continente: cada día somos más pobres, vemos la miseria, conocemos la caída del tobogán. Quizás algunos se sientan contentos por esto.

¿Qué libros prefiere leer?

Todos los míos. Me entusiasma leerme a cualquier hora. Especialmente de noche. Es la única forma que encontré para no conciliar el sueño. También leo otros, de ciertos uruguayos que nadie conoce, de esos autores que no están en las librerías (porque ya no hay librerías), que no llegan al resto del país (la capital es el país), que no cruzan el Río de la Plata, que no recorren los países "hermanos" de Latinoamérica.

Todavia no hemos hablado sobre qué escribe.

Generalmente sobre una mesa.

Pero ¿qué escribe?

Tampoco ahora puedo ser original. Ve usted, también esto ya lo he dicho. Yo escribo lo que puedo y no lo que quiero. Y generalmente puedo escribir de una 
niña rubia violada, de la relación de una cura tuerto con su monaguillo pecoso o del amor que mi padre no me mostró. A veces me gustaría divertirme cuando hago literatura, pero no hay caso, no puedo. Por eso perturbo.

Si tuviera que llevarse un libro a una isla ¿̇cuál elegiría?

No elegiría ni un solo libro. Me inclinaría por los discursos de los políticos profesionales (orientales, muy orientales), por los diarios de sesiones de las Cámaras (orientalísimas) y por las versiones grabadas de dos o tres programas radiales y televisivos (uruguayísimos). Como no encuentro mejor literatura de humor en mi país, estoy seguro de que sería lo único que me permitiría combatir la tristeza y la depresión de la soledad.

¿Cómo pasó durante la dictadura? ¿Estuvo preso? escribir.

Fui destituido de mi cargo público y estuve preso tres días, pero no por

¿Eso es todo lo que puede decir?

Prefiero olvidar. Pero voy a hacerle una confesión que le demostrará por qué no puedo ir preso por escribir. Yo escribo en estado de necesidad. Hay una figura jurídica que así se llama, algo similar a lo que es la legítima defensa. Un padre de familia, por ejemplo, rompe una vidriera y roba todos los alimentos que en ella se exhiben para alimentar a sus hijos que padecen hambre. Ese hombre no irá preso, el delito de hurto desaparece si este extremo del estado de necesidad llega a probarse. Esto es lo que me pasa con la literatura. No es que tenga hambre (mi familia tampoco, por ahora, al menos), pero yo tengo que defenderme, responder a las agresiones, alimentarme para continuar respirando y conservar fuerzas para el grito.

¿De qué trata de defenderse?

Del hombre, del ser humano, de esto que somos usted y yo. De ese ser que nace al cabo de nueve meses (generalmente), del niñín que provoca risas, felicitaciones, lágrimas de alegría. De ese extraño ser que años después coloca una bomba en un avión para que en el acto mueran doscientas personas, humilla al prójimo, lo explota o se proclama amo y señor de veinte millones de habitantes de un país. De la estupidez, de la complicidad, de la venalidad, de la ramplonería, de la ignorancia supina, de la crueldad. De todo eso y de algo más.

Sin embargo, usted olvida todo lo positivo que ha logrado el hombre.

Si usted hubiera leído algo de lo que he escrito, no me obligaria a repetirme. En ese sentido se parece a los periodistas más típicos que he conocido. De todos modos, le digo que no olvido nada. Sólo que yo preferiría que la tragedia del nazismo, por ejemplo, no hubiera sucedido. Y esto aun en el caso de que para ello fuera necesario que el "Réquiem de Mozart" se borrara desde la primera hasta la última nota. O que el Líbano siguiera siendo un país y no un conjunto de escombros bien apilados. Aunque no se hubiera inventado el avión. No sé por qué diabólica razón siempre olvidamos que el único culpable es el hombre, el mismo que nació después de una relación de amor hirviente. ¿Cuántas veces oyó hablar del hombre nuevo? Lo anuncian permanentemente, hasta lo ubican en 
algún país en especial. ¿De qué hombre nuevo hablan? Lean, por favor, los diarios de ayer, los de hoy, los de mañana. Verán qué terriblemente viejo es el hombre.

¿Considera que los concursos y los premios son necesarios?

$\mathrm{Si}$, especialmente cuando yo resulto premiado.

Pero ¿usted se ha presentado a concursos?

Pocas veces, otras me han premiado sin que lo hiciera. Voy a contarle algo. Hace poco tiempo, un integrante del jurado del premio Bartolomé Hidalgo, para el cual no hay que presentarse, gracias a los Santos Apóstoles (algo parecido a un Premio de la Crítica, sólo algo parecido), me dijo que no me habían dado el del año 1991 por Instrucciones para vivir, porque el año anterior yo había recibido por esa misma novela un premio muy importante (el Municipal). Y que dos premios importantes por unlibro era demasiado. ¿Se dacuenta? Son argumentos incontestables.

Sin embargo, usted ha integrado jurados.

Únicamente si me pagan.

Todavía no ha mencionado ni un solo autor. ¿No tolera la competencia?

La única competencia que no tolero es la de los profesores puestos a escritores para demostrar opiniones profesorales. Por supuesto que hay escritores con los que tengo muchos puntos en común, pero siempre me molestaron los reportajes sembrados de nombres, algo así como una demostración impúdica de todo lo que se ha leído. Conozco a quienes utilizan a los muertos - y también a los vivos, agonizantes o no- para calafatear sus dichos. Prefiero equivocarme solo.

Algún escritor uruguayo habrá que lo entusiasme especialmente.

Y sí, claro, pero ya los nombré una vez y me parece suficiente. ¿A quién le importa lo que a mí me importa? No espere que le diga los nombres mágicos. No espere que le diga los nombres. No espere. No.

¿Usted cree en el papel del lector?

Es en lo único en lo que creo. Yo tuve (a pesar de todo) críticas que podrían ser calificadas de "excelentes". Sin embargo, nada me ha levantado más el espíritu que escuchar comentarios de lectores desconocidos que se me han acercado para hablar de un texto que al fin de cuentas construimos entre todos. Entonces, no tienen lugar los pontífices, los sacerdotes que se creen con el derecho a interrumpir el sagrado silencio de una lectura, ese diálogo inefable entre autor y lector.

¿Cuál es la condición esencial para escribir?

No ser analfabeto.

¿Solamente?

Enamorarse de lo que se hace, con la misma ternura que si se tuviera enfrente a una pequeña de pelo largo, piel blanca, ojos claros, cuerpo delgado como una ramita y aire de fragilidad propio de una flor recién nacida. Y con la misma tristeza. Uno sabe que ese amor, como lo que se escribe, está destinado 
a desaparecer. Más tarde o más temprano todo se habrá olvidado. El que escriba para vencer el olvido está loco.

¿Entonces?

Que le doy a la máquina de escribir cuando no puedo más. Antes me lleno de vida, me cargo de tristeza, me hincho de placer, me inflo de dolor. Y de todo eso me enamoro. En el momento exacto, ni un minuto antes ni uno después, en el segundo preciso, antes de estallar, largo todo sobre la máquina. Y punto.

Para muchos usted es un escritor conocido jo cree que no lo es?

Escritores conocidos tenemos cuatro: tres viven en el Uruguay (aunque viajan frecuentemente) y el otro reside en el extranjero. Y está bien que así sea. Los demás o son desconocidos o son algo conocidos (por un grupo, por profesores, por estudiantes, por lectores de pura raza). Eso es todo. La única vez que yo me sentí escritor desde que me levantaba hasta que me acostaba fue cuando estuve invitado en la ciudad de Saint-Nazaire. Realmente lo fui. De esa experiencia nació Hombre sin palabras, curiosamente un personaje que enloquece porque no puede escribir de otra cosa que no sea su país. Pero, claro, Saint-Nazaire es Francia. Y Francia es Europa. Y Europa para muchos de nosotros es una mala palabra.

¿Por qué dice que está bien que sea así?

La literatura tiene que tener la misma variedad de clases que, por ejemplo, las telas. ¿Usted vestiría siempre de organdí? ¿De casimir? Dejemos que cada cual se ponga el escritor que más le siente. El libro hace un camino, tal como el del Señor, absolutamente imprevisible. Las grandes editoriales tratan de competir con esos caminos del Señor y trazan los propios. A veces son callejones sin salida. Yo prefiero (sé que algunos compatriotas no querrán creerme) el paso lento, terco y porfiado de las publicaciones domésticas. Cada centímetro que se avanza es realmente una superficie ganada. A puro esfuerzo del texto, sin intermediarios que hoy venden libros y mañana pueden fabricar calcetines. 
